\title{
LAS ESCRIBANÍAS COMO CONFLICTO ENTRE PODER REGIO Y PODER CONCEJIL EN LA CASTILLA DEL SIGLO XV: EL CASO DE CUENCA
}

\begin{abstract}
SUMARIO
Los protagonistas.- La provisión del oficio.- El pleito: La probanza de Diego de Valera. La probanza de Juan de Medina.- La solución del conflicto.- Conclusiones.
\end{abstract}

El reinado de los Reyes Católicos fue testigo de un firme proceso de reorganización y reordenación del reino castellano, tras la situación de caos y anarquía a la que se había llegado durante los últimos y calamitosos años de su antecesor, Enrique IV. Bien es verdad que no pudieron Isabel y Fernando asumir ese proceso sin chocar con la oposición y resistencia de ciertos sectores del reino, que no estaban dispuestos a tolerar que los soberanos, en ese intento por superar el estado de postración en que habían sumido al territorio castellano los débiles y abúlicos Juan II y Enrique IV, les obligarán a ceder toda una serie de derechos y privilegios que, bien por usurpación, bien por concesión regia, habían ido conquistando a lo largo de la primera mitad del siglo $\mathrm{XV}$.

En estas circunstancias, la regia pareja se vio obligada a iniciar una dura batalla, complicada por la existencia de diversos y sucesivos frentes, entre los que ocupa un lugar de importancia el relativo a la provisión de oficios. Efectivamente, tanto Juan II como Enrique IV habían procedido con excesiva ligereza en lo relativo a esa cuestión, permitiendo que se produjera una auténtica patrimonialización de los oficios, que eran renunciados, enajenados y colocados en manos de parientes y allegados por parte de aquéllos que los poseían.

La patrimonialización de los oficios supuso la presencia de toda una serie de problemas y dificultades, especialmente importantes en los casos de aquéllos cuyo ejercicio implicaba una necesaria cualificación previa. En esta situación se hallaban los oficios de escribanía, que precisaban contar con la presencia a su frente de hombres competentes, dotados de una formación específica y adecuada, que les facultara para el ejercicio de los mismos '.

' BONO, Historia del derecho notarial español, 2 vols., Madrid, 1982, estudia pormenorizadamente esta cuestión en el tomo II de su magistral obra, pp. 221 y ss. 
Así las cosas, los Reyes Católicos, cuando acceden al trono castellano, se encuentran con que el desorden y la irregularidad interna han hecho fuerte mella en el seno de la institución notarial, que se halla sumida en una gran confusión, a causa de las inadecuadas prácticas de provisión de los oficios a ella pertenecientes, la multiplicación de los mismos y su ocupación por escribanos inexpertos o carentes de la apropiada formación ${ }^{2}$, haciéndose evidente la necesidad de proceder a una profunda reforma de la institución notarial.

Ya en las Cortes de Madrigal de 1476 mostraron Isabel y Fernando su anhelo por devolver su perdido brillo a la institución notarial ${ }^{3}$; sin embargo, la reforma habrá de posponerse hasta las Cortes de Toledo de 1480 , en las que se dictarán toda una serie de medidas tendentes a implantar una "primera y eficaz política notarial castellana», basada en tres grandes puntales: el control numérico de los escribanos; su capacitación profesional; los procedimientos de acceso a los oficios de escribanía, lo que implica, por otra parte, un intento de los soberanos por controlar la provisión de aquéllos ${ }^{4}$.

Este intento de los monarcas por controlar el acceso a los oficios de escribanía se va a manifestar de forma ostensible en su intervención de cara a la provisión de escribanías públicas del número y escribanías concejiles. En efecto, los Reyes Católicos no dudan a la hora de disponer de dichos oficios, contraviniendo en muchas ocasiones las ordenanzas y privilegios de que gozaban los concejos de ciudades y villas, si bien lo cierto es que, con harta frecuencia, los concejos no habían podido disponer libremente de esos oficios, cuya provisión había recaído en las manos de prominentes miembros de la nobleza o de las oligarquías urbanas, que hacían y deshacían a su antojo, premiando con los mismos a sus criados, partidarios y allegados.

El caso es que este modo de proceder de Isabel y Fernando trajo aparejadas ciertas dificultades, derivadas, fundamentalmente, de los largos y costosos pleitos que iniciaban los concejos para tratar de hacer valer sus supuestos derechos al control del acceso a estos oficios. Justamente al mismo tiempo que en Toledo tenían lugar las Cortes en las que se iban a sentar las bases para la reforma de la institución notarial, se sustanciaba ante el Consejo un proceso

2 La situación es descrita con negras tintas en J. BONO, Op. cit., 276 y ss., II. Ver, también, F. ARRIBAS ARRANZ, Los escribanos en Castilla en el siglo XV, "Centenario de la Ley del Notariado", Madrid, 1963, I, Sección Histórica.

${ }^{3}$ En dichas Cortes se hace ya una clara alusión a la necesidad de la reforma, si bien se pospone hasta mejor ocasión, limitándose los soberanos a afirmar que su intención, de cara al futuro, es "proveer como cunpla a nuestro serviçio e al bien e pro común de nuestro rreynos», Cortes de los antiguos reinos de León y Castilla, IV, Madrid, 1882, p. 106, núm. 39.

4 Seguimos en esta materia el sobrio y acertado resumen que de la reforma de la institución notarial realizada por los Reyes Católicos hace J. BONO, Op. cit., pp. 291 y ss., II. 
que, en última instancia, ejemplifica esta lucha entre la corona y los concejos.

El citado pleito, que va a ser objeto de estudio en este trabajo, tiene como objetivo dirimir a quién corresponde la escribanía del concejo de la ciudad de Cuenca, si a Diego de Valera, provisto del oficio por los propios soberanos, o a Juan de Medina, elegido por los regidores conquenses para ejercer la susodicha escribanía. La fuente que permite acceder a los detalles del suceso es un expediente conservado en el Archivo General de Simancas, Sección de Cámara de Castilla/Personas, legajo 29, correspondiente a Diego de Valera. Aunque, desafortunadamente, no está completo, sí se conservan las partes esenciales del mismo, que, unidas a algunos documentos procedentes del Registro General del Sello de ese mismo Archivo, permiten reconstruir la totalidad del proceso.

\section{LOS PROTAGONISTAS}

Tanto Juan de Medina como Diego de Valera son dos personajes que permanecen prácticamente en el anonimato, siendo muy escasos los datos relativos a ambos que traslucen a lo largo del proceso, que apenas ofrece detalles acerca de sus dos grandes protagonistas.

En cuanto a Diego de Valera, hay que resaltar, en primer lugar, que, pese a la coincidencia de nombre, apellido y naturaleza, nada tiene que ver con su famoso homónimo, cronista de Juan II, Enrique IV y los Reyes Católicos, a la par que uno de los más interesantes prosistas de la Castilla del siglo XV. Efectivamente, este último, nacido en el año 1412 ', era ya un anciano en el momento en que tiene lugar el pleito, mientras que el Diego de Valera que pretendía la escribanía del concejo de la ciudad de Cuenca era un hombre muy joven, hasta el punto de que su adversario no duda en descalificarle por su condición de mancebo, pues su poca edad le parece poco acorde con las elevadas cualidades que se le habían de exigir a un escribano.

Tampoco es factible que el joven aspirante a escribano y su anciano homónimo estuvieran unidos por lazos familiares. No se puede olvidar que este segundo no llevaba el apellido Valera por nacimiento, pues lo había adoptado

' Sobre Diego de Valera hay toda una serie de estudios de interés; destacaremos aquí el realizado por su primer biógrafo, L. de TORRE, Mosén Diego de Valera. Apuntaciones biográficas, Madrid, 1914, así como el más completo debido a la pluma de J. M. CARRIAzo, en su introducción a su edición de una de las más destacadas obras cronísticas de Valera, la Crónica de los Reyes Católicos, publicada en Madrid, el año 1941. Una puesta al día bibliográfica sobre el personaje en M. P. RABADE, Los conversos en la Corte y en la época de los Reyes Católicos, Madrid, 1990. 
en el año $1421^{\circ}$, probablemente por tratarse de un gentilicio muy prestigiado en su ciudad natal, ya que los Valera eran uno de los más destacados linajes conquenses '. No es este el caso de su joven homónimo, que había recibido el apellido de su padre, Juan de Valera. En cuanto a su posible pertenencia a la poderosa y acaudalada familia Valera, nada se puede decir con seguridad, si bien tampoco se ha de descartar que así fuera, hipótesis abonada por la más que acomodada situación económica del mancebo, así como por sus contactos con algunos de los más destacados ciudadanos conquenses, y por su adscripción a la parroquia de San Miguel, una de las más prestigiosas colaciones de la ciudad de Cuenca ${ }^{8}$.

Pocos datos más acerca de la familia de Diego de Valera se pueden extraer del proceso. Su padre era hijo de Juan Sánchez de Valera y de una anónima dama cuyo nombre no se refiere en ningún momento; igualmente, el pleito afirma que Juan de Valera tuvo al menos un hermano, Alonso de Valera. El proceso no ofrece ninguna información acerca de las actividades profesionales del progenitor de Diego, y tampoco refiere la fecha en la que se produjo su óbito, pues Juan de Valera ya era difunto en el año 1480, aunque el hecho de que su viuda -cuyo nombre no se cita en ningún momento- estuviera casada en segundas nupcias con un tal Juan de Pareja parece indicar que el fallecimiento había tenido lugar tiempo atrás. Por lo demás, la lectura del proceso hace pensar que Diego tenía un único hermano, Felipe de Valera '; ambos hermanos estaban "coronados», sin que pueda establecerse si los dos o alguno de ellos habían recibido las órdenes mayores. Diego no estaba casado, pero esta

${ }^{6}$ Efectivamente, tal como nos informa un documento conservado en el Archivo General de Simancas, Mercedes y Privilegios, lg. 2, núm. 224, y datado en la citada fecha, Valera vivió los primeros años de su vida bajo el nombre de Diego Alonso de Guadalajara. Sin embargo, por razones desconocidas, aunque posiblemente -tal como ya queda dichoguiado por la sonoridad que el apellido Valera tenía en su ciudad natal, decidió adoptar ese segundo gentilicio, obteniendo permiso para ello de Juan II.

' A. GonZÁlez Palencia (dir.), Biblioteca conquense, II, Cuenca, 1953, p. 240 y siguientes, coloca a los Valera entre los más destacados linajes de la urbe, aportando algunos interesantes datos sobre la familia. Por su parte, J. MOYA PINEDO, Corregidores y regidores de Cuenca (siglos XV al XIX), Cuenca, 1977, p. 14, analiza brevemente la figura de Juan Fernández de Valera, el miembro más destacado del linaje durante el siglo XV.

${ }^{8}$ F. PINEL Y MONROY, Retrato del buen vasallo, Madrid, 1667, al realizar la biografía de otro ilustre conquense, recuerda, en la p. 37 de su obra, que la parroquia de San Miquel era una de las más prestigiosas de la ciudad de Cuenca, por la calidad de las gentes que habitaban en la demarcación de la colación a la que daba nombre.

${ }^{9}$ Es el único hermano de Diego de Valera que se menciona a lo largo del proceso. Por otra parte, tal como se verá más adelante, Diego y Felipe se habían repartido a medias los bienes patrimoniales heredados de su padre, lo que parece indicar que, o bien eran sólo dos hermanos, o bien tan sólo ellos dos habían logrado llegar a la edad adulta. 
circunstancia podría deberse, más que otra cosa, a su extremada juventud ${ }^{10}$.

En cuanto a las actividades profesionales de nuestro hombre, poco es lo que aclara el pleito, que se limita a señalar que Diego era criado del Doctor Rodrigo Maldonado de Talavera. No obstante, la parquedad de nuestra fuente principal queda paliada gracias a la información que sobre Diego de Valera nos suministran las Cortes de Toledo de 1480, según las cuales era «escrivano del rey e de la reyna nuestros sennores e su escrivano e notario público en la su Corte e en todos los sus reynos e sennoríos»".

Tampoco es posible conocer con detalle la situación económica de Valera, si bien todo parece indicar que era bastante saneada. El mismo, en la segunda pregunta del interrogatorio que encabeza su probanza, afirma poseer bienes patrimoniales por valor de unos 150.000 maravedíes, cosa que parecen confirmar la mayor parte de sus testigos. En este sentido, destacan las declaraciones de uno de ellos, Nicolás López, escribano público y vecino de la ciudad de Cuenca, que describe brevemente las posesiones de Diego: la mitad de las casas en las que moran su madre y su padrastro, Juan de Pareja; la mitad de un horno en la calle de San Pedro; unas tablas de carnicería y dos pares de casas en las proximidades de la Puerta de Valencia; la mitad de una heredad que su padre poseía en Villar de Santa Olalla, juntamente con la mitad de las casas allí edificadas, y el ganado que tenían en la citada heredad, compuesto por ovejas, vacas y bueyes. Por su parte, otro testigo de su probanza, Juan de la Bachillera, precisa que eran unas ochocientas las cabezas de ganado ovino que poseía.

Menos aún se sabe de Juan de Medina, que omite en el interrogatorio con que se inicia su probanza prácticamente cualquier detalle respecto a sí mismo. Desde luego, era, como el anterior, vecino de la ciudad de Cuenca, y da la impresión de que se le ha de situar en el seno de la oligarquía urbana conquense, ya que cuenta con el apoyo de ilustres personajes de la localidad. Al mismo tiempo, aunque no se ofrecen datos acerca de su situación económica, parece evidente que ésta era buena, pues Medina podía manejar, si las circunstancias lo precisaban, grandes cantidades en metálico, tal como ya se indicará más adelante.

Cuando tiene lugar el pleito era un hombre ya de cierta edad, pues tenía un hijo casadero, Juan Ramírez de Medina, que, además, tenía quizá edad

${ }^{10}$ Recuérdense las peculiares condiciones de los «coronados», que recibían las órdenes menores y la tonsura o "corona" con objeto de disfrutar de las ventajas a las que les daba acceso esa situación, entre ellas la de acogerse a la jurisdicción eclesiástica. La mayor parte de ellos no recibían las órdenes mayores, por lo que no estaban obligados al celibato, como tampoco eran, en sentido estricto, clérigos.

"Cortes de los antiguos reinos de León y Castilla, IV, Madrid, 1882, p. 194, en la que Diego estampa su firma, en calidad de escribano. 
suficiente para ejercer el oficio de escribanía al que aspiraba su padre, pues el íntimo deseo de éste era, una vez conseguido el oficio, renunciarlo en su hijo. Se desconoce todo lo relativo a su desempeño profesional, sin que pueda establecerse, por tanto, si estaba relacionado con la institución notarial. Lo que sí parece bastante posible es que se trate del mismo Juan de Medina que, durante el reinado de Enrique IV, era guarda y vasallo de este soberano, así como su juez en la ciudad de Cuenca y su Tierra ${ }^{12}$; además, esto cuadraría con la imagen de hombre poderoso y de medios económicos que de Juan de Medina nos da el pleito.

\section{LA PROVISIÓN DEL OFICIO}

En un momento indeterminado del año 1479 , que hay que situar poco antes del doce de diciembre, se produce en Cuenca el fallecimiento de Luis de Chinchilla, escribano del Concejo de dicha ciudad ${ }^{13}$. Este óbito supone el inicio de la lucha por la posesión de su oficio de escribanía, que se disputan Diego de Valera y Juan de Medina. El inicio de la disputa que enfrentará a ambos hay que situarlo en dos hechos que van a mediatizar toda la cuestión: la provisión que los Reyes Católicos hacen del oficio en favor de Diego de Valera; la elección efectuada por los regidores conquenses en orden a cubrir la vacante, elección que favorece a Juan de Medina.

El 17 de diciembre de 1479, en Toledo, Isabel y Fernando hacen merced a Diego de Valera de la escribanía del concejo de la ciudad de Cuenca, por muerte de su anterior poseedor, Luis de Chinchilla ${ }^{14}$. Realmente, si hemos de creer los datos que aporta en su probanza Juan de Medina, la merced le había sido concedida de antemano, antes incluso de que hubiera tenido lugar el óbito de su antecesor ". Si la reconstrucción que hace Medina de los hechos es cierta, Diego de Valera, sabedor de la grave enfermedad que atenazaba a Chinchilla,

${ }_{12}$ J. Moya Pinedo, Op. cit., pp. 5 y 13.

${ }_{13}$ No se trata de un escribano público o del número de la ciudad, sino de un oficio de escribano del concejo, encargado de llevar cuenta "de los fechos e negoçios del conçejo de la dicha çibdat». El mismo pleito insiste en que se trata de oficios distintos, si bien J. BONO, Op. cit., II p. 143 y ss., no alude, al referirse a los escribanos de nombramiento ciudadano, a la existencia de los escribanos de concejo. Estos son, sin embargo, protagonistas de la monografía de E. CORRAL GarCía, El escribano de concejo en la Corona de Castilla (siglos XI al XVII), Burgos, 1987. En cuanto a la fecha del fallecimiento de Luis de Chinchilla, se puede fijar, con cierta aproximación, gracias a los datos que se nos ofrecen a lo largo del pleito.

${ }_{14}$ Archivo General de Simancas, Registro General del Sello, Toledo, 17-12-1479, fol. 1.

1s En la probanza de Juan de Medina se ofrecen diversos testimonios en este sentido. Destaca el de Lope de la Barrera, que asegura que el propio Valera se vio obligado a reconocer que la fecha de la merced estaba en blanco. 
decidió hacerse valer en la Corte, utilizando sus influencias para inclinar la provisión del oficio a su favor.

Aprovechando su privanza con el Doctor de Talavera, logró que éste le consiguiera de los soberanos la expectativa que le facultaba para acceder al oficio de escribanía del concejo de la ciudad de Cuenca, una vez que se tuviera noticia del fallecimiento de su actual poseedor. Al conceder dicha expectativa, los Reyes Católicos no dudaban en mantener una práctica que va a ser anatematizada en las Cortes de Toledo. Efectivamente, uno de los resultados de aquella asamblea será la supresión de las cartas de expectativa, pues de sus consecuencias «se siguen muchos e grandes dannos a la república e muchos inconvinientes entre nuestros súbditos e naturales. Así, se revocan todas las cartas de expectativa concedidas de antemano por los propios monarcas y que aún no habían tenido efecto, y se establece que dichas cartas no serán otorgadas en lo sucesivo ${ }^{16}$.

A pesar de que los soberanos reconocen explícitamente que ellos también habían entregado cartas de expectativa durante los primeros años de su reinado, resulta un tanto sorprendente que, ya en los últimos días de 1479 , se siguieran otorgando aquéllas, a pesar de que ya debía ser notorio el proyecto de su inmediata supresión. Probablemente, la expectativa con que se favoreció a Diego de Valera fue una de las últimas concedidas por Isabel y Fernando, y tal vez haya que atribuirla a la privanza que, según algunos de los testigos aportados por Juan de Medina, tenía el joven escribano con la reina ${ }^{17}$.

La existencia de la expectativa en favor de Valera se hizo pública en Cuenca cuando, en fecha igualmente indeterminada, se personó en la Corte Juan de Huesca, comisionado por Luis de Chinchilla. Este, gravemente enfermo, deseaba, antes de morir, renunciar su oficio en favor de su futuro yerno, Juan Ramírez de Medina, hijo de Juan de Medina. Huesca, pues, viajaba a la Corte para obtener a Chinchilla facultad de los monarcas para renunciar su oficio en Juan Ramírez de Medina. Tras unos días de estupor, en los que el anciano escribano se interrogó acerca de la personalidad de aquél que había sido designado como su sucesor ${ }^{18}$, Chinchilla decidió pasar a la acción, secundado por el concejo conquense, que no estaba dispuesto a tolerar el atropello.

También en fecha indeterminada, fue enviado a la Corte Diego del

16 Cortes de los antiguos reinos de León y Castilla, IV, Madrid, 1882, pp. 159 y ss.

17 Tal asevera Juan de Chinchilla, hijo de Luis de Chinchilla, presentado como testigo por Juan de Medina.

18 Otro de los testigos aportados por Medina, el bachiller Pedro de Alcocer, recuerda cómo Chinchilla creyó, en un primer momento, que el Diego de Valera que había obtenido merced de su oficio era el yerno de otro vecino de Cuenca, Luis de Alcalá, que se apresuró a sacarle de su error. 
Castillo, canónigo de la Iglesia Catedral de Cuenca, con el encargo de realizar averiguaciones sobre lo sucedido. El canónigo, al informarse de la cuestión, descubrió que había sido el Doctor de Talavera el que había conseguido el oficio, para colocarlo en manos de un criado suyo; en esas circunstancias, fue a hablar con el letrado, tratando de llegar a una solución amigable del asunto, aunque sin conseguir nada positivo, pues Talavera insistía en que se había hecho gracia del oficio a Valera en la seguridad de que su antecesor ya había fallecido, por lo que la única posibilidad era concertarse con el propio Valera. Así lo intentó Castillo, pero sin éxito, pues Diego exigía, para abandonar sus pretensiones, una crecida indemnización; consciente de la importancia económica del oficio, que él valoraba en unos 160.000 maravedíes, reclamaba que se le pagara una cantidad mínima de 50.000. Por su parte, sus oponentes le ofrecían quince doblas de oro.

Fracasado el intento de negociación, el canónigo se dirigió a un viejo conocido suyo, el Doctor Juan Díaz de Alcocer, que le acompañó ante el rey, a quien se comunicaron las circunstancias del caso, poniéndose especial énfasis en el hecho de que Luis de Chinchilla estuviera aún vivo, al tiempo que se le rogaba efectuara la provisión del oficio tal como el todavía escribano del concejo de Cuenca deseaba. Sin embargo, el monarca insistió en que ya se había hecho merced del oficio, al tiempo que afirmaba que se había otorgado en la seguridad de que su anterior poseedor había pasado a mejor vida. A pesar de esa primigenia seguridad, y ante la duda planteada por la intervención del Doctor de Alcocer, Fernando comisionó a éste para averiguar si en verdad estaba vivo Luis de Chinchilla.

Lo cierto es que esas averiguaciones jamás se llevaron a cabo, pues Chinchilla murió apenas dos o tres días después. Según su hijo, Juan de Chinchilla, testigo presentado por Juan de Medina, los hechos relatados adelantaron su muerte. Pero ni Juan de Medina ni el Concejo de la ciudad de Cuenca, que le apoyaba, estaban dispuestos a rendirse sin luchar; de modo que el óbito de Luis de Chinchilla fue seguido, de forma casi inmediata ${ }^{19}$, por una reunión de los regidores de la ciudad, que se juntaron para, en virtud de unas antiguas ordenanzas conquenses, elegir una terna -Juan de Medina, Alonso de Ocales y Pedro de Chinchilla- que había de ser presentada ante los soberanos para que éstos proveyeran el oficio en uno de esos tres hombres. La suplicación en ese sentido, fechada en Cuenca, a doce de diciembre de 1479, fue presentada ante la Corte, en Toledo, diez días después.

El pleito se hace inevitable, debido al encono de las dos partes, pues ambas

19 Según otro de los testigos presentados por Juan de Medina, Alonso Ramírez de Huete, la elección se hizo a los dos o tres días del óbito de Chinchilla, apresuradamente, debido a que ya era público y notorio lo que sucedía con la sucesión del oficio. 
tratan de hacer valer sus derechos, mostrándose poco dispuestas a dar su brazo a torcer; si bien Diego de Valera contaba a su favor con la merced que le habían hecho del oficio los Reyes Católicos, Juan de Medina, que hace que su hijo sea relegado a un segundo plano desde el momento mismo de la muerte de Luis de Chinchilla, tiene el apoyo del concejo de Cuenca, que se niega a recibir a Valera en el oficio ${ }^{20}$. En esas circunstancias, será la justicia la que habrá de decidir cuál de los dos antagonistas es el que tiene más derecho al oficio en litigio.

\section{EL PLEITO}

Aunque no resulta posible determinar en qué fecha exacta se produce el comienzo del pleito, lo que se hace evidente es que éste ya se había iniciado con los primeros días del año 1480. Indudablemente estaba ya en marcha el décimo cuarto día del citado mes, pues es entonces cuando los Reyes Católicos disponen que se ponga en secuestración el oficio de escribano del concejo de la ciudad de Cuenca, vacante por muerte de su poseedor, hasta que el Consejo decida en el pleito sustentado por la posesión del citado oficio ${ }^{21}$.

Otro indicio de que el pleito ya se había iniciado es el escrito que, ese mismo día, presenta Juan de Medina ante el Consejo, exponiendo los problemas que a él y al concejo de Cuenca les estaba planteando la elección de un letrado que ostentara su representación legal durante el mismo. Nadie quería hacerse cargo de la misma, "por que todos los dichos letrados disen que son amigos del dicho dotor (de Talavera), e que tienen cargos reçebidos del, e que en ningund caso e por ningund presçio non ayudarían contra el dicho Dyego de Valera, nin contra cosa que al dicho dotor tocase». El Consejo, atento a los derechos de ambas partes, se apresura a designar un letrado a Juan de Medina y al concejo de Cuenca, recayendo su elección en el Doctor de Monzón. Si bien el proceso ya había empezado su andadura, lo cierto es que este escrito produce en el lector la impresión de que aquélla se encontraba en sus prolegómenos.

Se desconoce el nombre del letrado que se hizo cargo de la otra parte litigante, si bien el hecho de que Diego de Valera disfrutara del apoyo del Doctor de Talavera hace pensar que no debió ser el suyo un letrado cualquiera, aunque no es posible que fuera el propio Rodrigo Maldonado de Talavera, pues

20 Valera pondrá en conocimiento de los monarcas esta situación, quejándose amargamente del agravio que se le hacía, solicitando sobrecarta de su merced para el concejo de Cuenca, en un escrito presentado ante el Consejo en Toledo, el nueve de enero de 1480. 159.

${ }^{21}$ Archivo General de Simancas, Registro General del Sello, Toledo, 14-1-1480, fol. 
éste, en su calidad de miembro del Consejo, ante el cual se sustanciaba el pleito, debía mantenerse -al menos, en teoría- absolutamente imparcial ${ }^{22}$.

En los días subsiguientes al catorce de enero, tanto Diego de Valera como Juan de Medina presentaron ante el Consejo sendos escritos, en los que exponían su versión de los hechos, resaltando sus derechos al oficio y descalificando los argumentos de la parte contraria ${ }^{23}$. Vistas las alegaciones de ambos, Isabel y Fernando comisionan al bachiller Martín del Castillo, alcalde de Cuenca por el caballero Juan de Osorio (corregidor de la ciudad y su Tierra en nombre de los Reyes Católicos), y al bachiller Fernán Sánchez, prior de Belmonte y canónigo de la Iglesia Catedral de Cuenca, para que realicen la prueba testifical del proceso ${ }^{24}$.

Ese mismo día, ante la imposibilidad de permanecer en la Corte mientras se sustanciaba el pleito, Juan de Medina nombró procurador a Juan de Huesca, que ya debía estar entrenado en gestiones cortesanas; su actuación se reducirá, además, a ese ámbito, pues en Cuenca vamos a ver a Medina actuando personalmente ${ }^{25}$. El de Diego de Valera es el caso opuesto; nombra procurador a su hermano Felipe de Valera, para que éste realice todas las gestiones pertinentes en Cuenca, mientras que él mismo en persona se encargará de gestionar las que tengan la Corte por escenario ${ }^{26}$.

22 La documentación contenida en el expediente estudiado demuestra que el Doctor de Talavera no se inhibió en el pleito, sino que participó en el mismo en su calidad de miembro del Consejo. De todas formas, los problemas de Medina para hallar letrado que le representasa tampoco se han de considerar como indicios de que Talavera presionaba en favor de su criado.

23. Valera presentó ante el Consejo un escrito en este sentido el diecisiete de enero, mientras que Medina lo hizo al día siguiente. Se encuadran en la larga y reiterativa serie de escritos que ambos contendientes hicieron llegar al Consejo desde los primeros días del mes de enero y hasta que el pleito quedó visto para sentencia.

${ }^{24}$ Archivo General de Simancas, Registro General del Sello, Toledo, 1-2-1480. La sentencia del Consejo, recibiendo a ambas partes a la prueba y dándoles término para presentar sus interrogatorios de probanza y testigos, fechada en Toledo, a 25 de enero de ese año, y comunicada a los afectados seis días después, está contenida en nuestra fuente principal.

2s Huesca, escudero y secretario de Juan de Medina, recibe su carta de procuración en Cuenca, el 29 de enero de 1480 . No sólo representará a su señor, sino también a Alfonso de Ocales y Pedro de Chinchilla. Su relación con Medina hace pensar que su presencia, meses atrás, en la Corte, con objeto de solicitar para Luis de Chinchilla facultad para renunciar su oficio en quien él deseara, debió estar matizada por la personalidad del beneficiario de dicha facultad, el hijo del propio Juan de Medina.

${ }^{26}$ En el expediente no consta la carta de procuración, muy probablemente porque Felipe de Valera no actuó como procurador de su hermano en la Corte sino en Cuenca, con lo que el documento no se adjuntó al expediente reunido por el Consejo. Al menos desde el día 7 de febrero de 1480 estaba usando de su condición de procurador de Diego, a tenor de la fecha en la que presentó la carta de receptoría de testigos en nombre de su hermano. 
Ha llegado, para ambas partes, el momento de la presentación de sus probanzas.

\section{La probanza de Diego de Valera}

Diego de Valera encabeza su probanza ${ }^{27}$ con un interrogatorio compuesto por dieciseis preguntas, cuyos contenidos podemos agrupar en cuatro grandes apartados:

1) cuestiones destinadas a demostrar que ni Juan de Medina, ni los otros dos miembros de la terna elegida por los regidores conquenses -Pedro de Chinchilla y Alonso de Ocales- están capacitados para ejercer un oficio de escribanía.

2) preguntas orientadas a demostrar que Diego de Valera, por contra, sí está facultado para desempeñar el dicho oficio.

3) cuestiones relativas a la manera en que se había provisto el oficio hasta la fecha, resaltando que dicha provisión había estado en manos de los monarcas.

4) preguntas dirigidas a demostrar que Luis de Chinchilla y Juan de Medina se habían concertado, durante la enfermedad del primero, para que el hijo del segundo obtuviera el oficio de escribanía del concejo de Cuenca, a cambio de determinadas contrapartidas, propiciando con su actitud la realización de una elección fraudulenta por parte de los regidores conquenses.

Pocos son los argumentos que ofrece Diego de Valera para descalificar a sus contrarios. Un primer argumento, dirigido exclusivamente contra Pedro de Chinchilla, es que éste no sea vecino de la ciudad de Cuenca, sino de un lugar de la tierra de Huete, donde tiene su residencia habitual, en la que habita con su mujer e hijos. Todos los testigos presentados por Valera corroboran esta aseveración. La importancia que se concede a esta cuestión hemos de relacionarla con el interés que parece tener Diego por demostrar que no sólo es vecino de Cuenca, sino que también lo fueron su padre y su abuelo.

Esta importancia que parece concederse al enraizamiento del futuro escribano en la ciudad de Cuenca hay que ponerla en relación directa con uno de los requisitos personales que habitualmente se exigían al notario: su avecindamiento en la localidad donde había de ejercer el oficio, requisito que a veces se ampliaba, llegando a implicar no sólo la vecindad, sino también la naturaleza,

${ }^{27}$ Presentada ante el Consejo, en Toledo, a 28 de febrero de 1480. Testificaron a su favor: Juan Álvarez, regidor de Cuenca; Juan del Escuela; Juan de Sacedón, regidor de Cuenca; Juan de la Bachillera; el bachiller Pero Jiménez; el regidor Gonzalo de Beteta; Mari Sánchez de Sarrión, hija de Juan Sánchez de Sarrión; Doctor Alfonso de Toledo; Juan de Carvajal, criado de Lope Vázquez de Acuña; Luis de Alcocer; Nicolás López, escribano del número de Cuenca; Juan Álvarez de Salas; Pedro de Acuña, Conde de Buendía. 
bien relativa a la localidad concreta donde se iba a desempeñar la escribanía, bien a la comarca en la que se asentaba ${ }^{28}$.

Evidentemente, la residencia en la ciudad de Cuenca debía contemplarse como una de las indispensables formalidades que se habían de requerir a todo el que pretendiera poseer el oficio de escribano de su concejo, e incluso también es posible que se valorara positivamente el enraizamiento familiar en la urbe, pues sólo eso explicaría el afán de Valera por aclarar que su abuelo y su padre habían sido ya vecinos de la ciudad. Sin embargo, esto entraría en flagrante contradicción con las circunstancias personales del propio Valera, pues todo parece indicar que el joven escribano, aunque vecino de Cuenca, residía habitualmente en la Corte, junto a su señor, el Doctor de Talavera; bien es verdad que esto tampoco era óbice, pues no habría sido el primer caso en el que un escribano del concejo de Cuenca no hubiera residido en la ciudad, sirviendo el oficio por medio de un lugarteniente ${ }^{29}$.

Cercenadas -desde el punto de vista de Valera- las posibilidades de acceso al oficio de Pedro de Chinchilla, debido a no estar avecindado en Cuenca, nuestro hombre se lanza, a continuación, a probar que tampoco Juan de Medina y Alonso de Ocales están capacitados para ejercer la profesión de escribanos. En este caso, Valera se aferra a argumentos menos formalistas y de más peso: Medina y Ocales «no saben escrevir segund al dicho of ç̧io conviene, nin tienen esperiençia alguna del dicho ofiçio de escrivanía para saber usar del dicho ofiçio; sy saben escrevir es muy poco, e de tan mala letra que no son pertenesçientes ni abiles para tener nin gosar del dicho ofiçio»

Se centra Valera en dos aspectos fundamentales, dentro de los requisitos de aptitud ${ }^{30}$ que se exigían al notario: por una parte, el estar en posesión de un acurado conocimiento del arte de la escritura, conocimiento que debía de ir convenientemente acompañado por una buena caligrafía, una de cuyas características esenciales debía ser su legibilidad; por otra, el haber recibido la formación adecuada, una formación basada de forma primordial en la experiencia que procuraban los años de aprendizaje junto a un maestro escribano, que iba enseñando pausadamente los secretos de la profesión a sus aprendices, transmitiéndoles los imprescindibles conocimientos gramaticales, jurídicos, etc... ${ }^{31}$.

28 J. BONO., Op. cit., pp. 219-220, vol. II.

29 Tal como ya se verá más adelante, tanto Juan de Sarrión como su hermano, Pedro de Sarrión, sirvieron el oficio recurriendo a ese sistema.

- J. BONO., Op. cit., II, pp. 211 y ss., divide las formalidades que el derecho notarial exige del aspirante a escribano en dos grandes apartados: requisitos personales y requisitos de aptitud; entre estos últimos incluye los relativos a la formación del futuro escribano, así como los contenidos que la conformaban.

${ }^{31}$ J. BONO., Op. cit., pp. 221 y ss., vol. II. 
Sin embargo, no se refiere Valera en ningún momento al examen que, al menos teóricamente, había de aprobar todo aquel que deseaba ejercer profesionalmente como escribano ${ }^{32}$. Parece evidente que ni Juan de Medina ni Alonso de Ocales se habían sometido a ese examen de capacitación profesional, pues en caso de que así hubiera sido, o bien se habría demostrado su aptitud para el desempeño del oficio, lo que habría invalidado las descalificaciones que contra ellos dirige su adversario, o bien -caso de no haber superado la prueba- su ineptitud sería algo público y notorio entre sus convecinos, lo que no sucede, pues éstos muestran una gran división de opiniones a la hora de calibrar la aptitud de ambos para el oficio de escribanía.

Así, tenemos opiniones para todos los gustos. Juan Álvarez no duda a la hora de afirmar que Medina y Ocales son hombres «honrrados e abonados para dar cuenta de sy en qualquier cosa", asegurando que el primero "escrive rasonablemente y es de los buenos contadores que ay en esta çibdad e su obispado", añadiendo que Ocales también sabe escribir. Muy otro es el parecer del bachiller Pedro Jiménez, que asevera que ambos «fasen muy mala letra, tal que pocos onbres podrán leerla»; piensa que no son hábiles para el oficio, porque nunca han usado de él, ni tienen ninguna experiencia relativa al mismo, lo que le parece imprescindible, terminando su declaración en torno a esta cuestión con una tajante apostilla, pues «es público y notorio» que si «alguna cosa oviesen de faser de qualquier calidad que tocase al dicho of f̧io, que non lo sabrían notar por sí mismos». Por su parte, Mari Sánchez de Sarrión, mujer de Diego de Velasco, el único testigo femenino de las dos probanzas, se desentiende de la cuestión, asegurando que ella desconoce si están capacitados para ejercer el oficio, o no.

Parece, pues, hacerse patente que era posible ejercer, si no todos, sí al menos ciertos oficios de escribanía sin acceder al desempeño de los mismos por medio de un examen de capacitación. De la innecesariedad de este examen en el caso concreto que estudiamos habla bien a las claras la probanza de Diego de Valera, en cuyas páginas se cuestiona la aptitud de Juan de Medina y de Alonso de Ocales para servir el oficio de escribanía del concejo de Cuenca, pero en ningún momento cifra Valera la descalificación de sus adversarios en el hecho de no haber superado el examen de capacitación profesional, y es ostensible que hubiera recurrido a este argumento si realmente hubiera sido de peso.

En cuanto a las razones sobre las que Diego de Valera asienta su aptitud de cara al ejercicio del oficio de escribano, hay que destacar que en ningún caso se detiene a considerar argumentos de carácter estrictamente profesional, si no que se inclina por ofrecer otros, claramente secundarios, pero que debían, obviamente, tener su peso, pues en caso contrario parece evidente que no

${ }^{32}$ Sobre este examen, ver J. BONO., Op. cit., pp. 228 y ss., vol. II. 
habrían sido mencionados. Es ahora cuando Valera insiste, tal como ya se ha dicho más arriba, en su condición de vecino, así como en el hecho de que tanto su abuelo como su padre también habían estado enraizados en la ciudad de Cuenca. A continuación, destaca sus bienes patrimoniales, que se elevan hasta una cuantía aproximada de unos 150.000 maravedíes, lo que hace patente su sólida situación económica.

Se trata de un elemento que no carece de importancia, pues, aunque en ningún momento se exigió al escribano estar en posesión de abundantes bienes patrimoniales, sí se observa una tendencia en este sentido, considerándose que aquél que poseía amplios bienes procuraría más honra al oficio que ejercía, al tiempo que estaría a salvo de posibles tentaciones y sobornos ${ }^{33}$. Desde luego, si Valera destaca este aspecto es porque sabe que se trata de una condición exigida a los escribanos, si no de derecho, sí de hecho.

Sorprende que el joven Diego no destaque aquí su condición de escribano de nombramiento regio, como sorprende, igualmente, que no se afane por demostrar su buenas cualidades profesionales, así como su experiencia en el ejercicio del oficio. Tal vez, estas aparentes carencias respondan al hecho de que Valera sea suficientemente conocido por los miembros del Consejo en su faceta profesional, por lo que se limita a dar a conocer detalles aparentemente secundarios, desconocidos para aquéllos que han de dirimir el pleito, detalles que pueden avalar su aptitud para el desempeño del oficio al que aspira.

Pasamos ahora al análisis de un punto esencial en la probanza de Diego de Valera, el relativo a la forma en que se cubría habitualmente el oficio de escribanía del Concejo de Cuenca. Efectivamente, se trata de la clave del proceso, pues Valera había accedido al mismo mediante gracia concedida directamente por los soberanos, de modo que si probaba fehacientemente que ese había sido el procedimiento habitual, su postura quedaba perfectamente legitimada, y el pleito se inclinaba, necesariamente, de su lado ${ }^{34}$.

Pero es que, además, también tiene que demostrar que son falsas las aseveraciones de su contrario, que no dudaba a la hora de proclamar que el oficio en litigio se había cubierto, desde el reinado de Juan II, según lo que disponían ciertas Ordenanzas que Fernando de Antequera, en sus días de regente de la Corona de Castilla, había otorgado a la ciudad, y ésta había guardado escrupulosamente hasta la fecha. De acuerdo con esas Ordenanzas, cada vez que vacara un oficio de escribanía del Concejo los regidores se reunirían para elegir una terna, y a continuación presentarían la terna ante el

${ }^{33}$ J. BONO., Op. cit., p. 220, vol. II.

${ }_{34}$ Evidentemente, no se trata de un procedimiento conforme a derecho, pero sí sancionado por la costumbre, con lo que esto implica en el siglo XV. 
monarca correspondiente, que proveería el oficio en la persona de uno de los tres componentes de la misma ".

Valera no pretende, en ningún momento, negar la existencia de las Ordenanzas otorgadas por Fernando de Antequera; pero lo que sí niega es que las susodichas Ordenanzas hubieran sido cumplidas de forma habitual, y, descendiendo a un plano más particular, afirma que jamás se habían cubierto las vacantes del oficio de escribanía del concejo según el procedimiento arbitrado por Fernando de Antequera, pues desde su promulgación y hasta el reinado de Isabel y Fernando el oficio siempre se había cubierto por designación regia, a petición de alguno de sus privados.

Para acreditar sus aseveraciones, Diego recontruye la historia de la provisión del oficio en litigio durante los últimos años, retrotrayéndose hasta 1436, año en el que se produjo el fallecimiento del escribano del concejo de Cuenca Juan López ${ }^{36}$. Vacante su oficio, éste se puso en manos de Juan Sánchez de Sarrión, pero no siguiendo lo dispuesto en las Ordenanzas de la ciudad, sino por merced del propio Juan II, que, por su lado, estaba actuando a instancias de parte. Efectivamente, fue Pedro de Acuña, Conde de Buendía y uno de los privados del monarca el que orientó la provisión; a su vez, el Conde respondía con su acción a la petición de su padre, Lope Vázquez de Acuña, regidor de Cuenca, que deseaba que el oficio recayera en Juan Sánchez de Sarrión, criado y parcial suyo.

Años después, la muerte de Juan Sánchez de Sarrión propició una segunda intervención del Conde, que se apresuró a solicitar merced del oficio al soberano, a lo que éste accedió, cubriendo la vacante el hijo del difunto, Juan de Sarrión, que era camarero del noble; esta provisión generó un cierto escándalo en la ciudad, pues el nuevo escribano del concejo no residía en Cuenca, ya que sus obligaciones para con el Conde le forzaban a permanecer continuamente junto a él. Sin embargo, el escándalo se acalló cuando Sarrión comunicó al concejo que, en su ausencia, sería Alfonso López de Santorcaz el que serviría el oficio ${ }^{37}$.

Pero no disfrutó Juan de Sarrión de su oficio durante mucho tiempo, pues

is El texto de este punto concreto de las Ordenanzas otrogadas a la ciudad de Cuenca por Fernando de Antequera se recoge en varios de los documentos contenidos en el expediente, y entre ellos en la suplicación que los regidores conquenses enviaron a Isabel y Fernando tras la elección de la terna de aspirantes a ejercer el oficio de escribanía del concejo de la localidad.

${ }^{36}$ No es posible determinar por qué ambos contrincantes inician su reconstrucción del procedimiento empleado para la provisión del oficio precisamente a partir del óbito de Juan López, aunque se puede deducir que si se hace así es porque fue la primera vez que vacó la escribanía tras la promulgación de las Ordenanzas de Fernando de Antequera.

${ }^{37}$ Tal como afirma la propia hermana de Juan de Sarrión, Mari Sánchez de Sarrión. 
no tardó en renunciarlo en su hermano, Pedro de Sarrión, aunque no se trata, realmente, de una concesión graciosa, pues lo cierto es que Pedro le compró el oficio a su hermano, abonándole por el mismo la cantidad de 30.000 maravedíes. Siendo también Pedro criado del Conde de Buendía, fue este segundo el que se encargo de solicitar a Juan II facultad para que Juan de Sarrión pudiera renunciar su oficio en su hermano sin sufrir trabas de ningún tipo. Pedro ejerció la escribanía personalmente durante algunos años, hasta que el Conde lo reclamó a su lado, circunstancia que le impelió a colocar el oficio en manos de un lugarteniente, Alfonso López de Santorcaz ${ }^{38}$.

Muerto Pedro de Sarrión, el Conde quiso hacer recaer la merced del oficio en la persona de su contador, Diego Alfón de Jaén; no obstante, en esa ocasión las cosas no salieron tal como el noble deseaba. El concejo no parecía estar dispuesto a seguir tolerando la conculcación de las Ordenanzas por las que se regía la ciudad, ni tampoco a permitir que los titulares de la escribanía del concejo siguieran residiendo fuera de la urbe, y ejerciendo el oficio por medio de lugartenientes. Además, a esto hay que unir los intereses personales de Luis de Chinchilla, que deseaba hacerse con el oficio.

Así, se llegó a una situación muy similar a la que se va a vivir casi treintta años después ${ }^{39}$, pues se produce la oposición entre Diego Alfón de Jaén, al que Juan II provee del oficio por instigación del Conde de Buendía, y Luis de Chinchilla, que recibe el apoyo del concejo conquense, pues también en esas circunstancias se recurrió a las Ordenanzas de Fernando de Antequera. Siguiendo el procedimiento descrito en las mismas, los regidores se reunieron para elegir una terna, que quedó compuesta por el propio Luis de Chinchilla, Luis de Molina y Alfonso López de Santorcaz. Posteriormente, se envió la suplicación a la Corte, con objeto de que el soberano proveyera el oficio en uno de los tres, si bien da la impresión de que la aspiración de los regidores era conseguir que la misma recayera en Chinchilla; no hay que descartar que el portador de la suplicación así lo indicara, o incluso que los otros dos miembros de la terna estuvieran dispuestos, en caso de ser elegidos, a ceder el oficio de Luis de Chinchilla, con la contrapartida de algún tipo de compensación.

Estaba por aquel entonces en la Corte Gonzalo de Beteta, regidor de Cuenca, pues era criado de Álvaro de Luna; emparentado con Luis de Chinchilla -era su cuñado- intentó romper una lanza en su favor, solicitando al Condestable que se proveyera el oficio en su persona. Luna le informó de que ya se había otorgado merced del mismo, pero el regidor insistió, destacando que la ciudad deseaba que el oficio lo ejerciera Chinchilla. En esas circunstancias, el

38 Según asegura Nicolás López, escribano del número de la ciudad de Cuenca.

39 La muerte de Pedro de Sarrión se produjo a lo largo del año 1452, según se asevera en la probanza de Juan de Medina. 
condestable le acompañó a solicitar la merced directamente del rey, pero éste corroboró las afirmaciones de su valido.

Cuando Beteta ya había perdido toda esperanza, una conversación con el secretario regio Bartolomé de Zafra cambió radicalmente el curso de la situación, pues el secretario, al cabo de las rivalidades mutuas que abrigaban Álvaro de Luna y Pedro de Acuña, y ansioso de favorecer al primero de los dos, se mostró dispuesto a abogar por la causa de Luis de Chinchilla ante el soberano, a cambio, eso sí, del pago de una sustanciosa cantidad; una vez abonada ésta ${ }^{40}$, Zafra tan sólo tardó unos días en colocar en las manos de Gonzalo de Beteta la provisión del oficio en favor de su cuñado.

Sin embargo, no todos los testigos aportados por Valera ofrecen esta versión de los hechos que condujeron a Luis de Chinchilla a ocupar la escribanía del concejo de Cuenca. Así, de acuerdo con la declaración de Juan de la Bachillera, Chinchilla compró, efectivamente, el oficio, pero estos tratos no le relacionaron con el secretario Bartolomé de Zafra, si no con el propio Diego Alfón de Jaén, al que entregó cien florines de oro y seis marcos de plata.

No obstante estas diferencias, todos los testigos de la probanza de Valera que manifiestan su conocimiento del suceso se muestran unánimes a la hora de afirmar que Chinchilla no accedió al oficio como consecuencia de la elección efectuada por los regidores conquenses, sino gracias a las maniobras que efectuó para lograr sus propósitos, y también, por supuesto, gracias a su saneada economía, que le permitió realizar un fuerte desembolso en pro de sus intereses.

Por otra parte, las contradicciones de los testigos pueden ser más aparentes que reales. No se puede descartar que Chinchilla accediera a la escribanía comprando los buenos oficios de Zafra, pero también otorgando una compensación económica a su oponente, compensación que podía significar la anuencia del contador, que prefería mejorar su economía y no lanzarse a un largo y desventajoso pleito por la posesión del oficio.

En cuanto al cumplimiento de las Ordenanzas, casi todos los testigos presentados por Diego de Valera están de acuerdo a la hora de declarar que nunca se habían guardado en su totalidad; tan sólo el testimonio del regidor Juan Álvarez escapa a esta tónica general, ya que no duda en asegurar que las ordenanzas se obedecieron siempre al pie de la letra. Juan del Escuela, por su parte, afirma que «las más de ellas, non se guardan en la vía e forma que en ellas se contiene». El Doctor Alfonso de Toledo va aún mas allá; tras exponer su

40 El regidor Gonzalo de Beteta, testigo presentado por Diego de Valera, que tanta parte tuvo en estos hechos, es el que nos pone al corriente de los pormenores del suceso, exponiendo, incluso, la cantidad que hubo de pagar Chinchilla para obtener el oficio, la manera en que reunió la suma y las condiciones en que efectuó el pago. 
parecer sobre las Ordenanzas, que «fueron con muy grand discreçión ordenadas e después muy mal executadas», añade que nunca se han cumplido por entero, fundamentalmente porque los regidores sólo las guardaban cuando les convenía; si no era así, recurrían contra ellas, bien directamente por su autoridad, bien -cuando eso no era posible- impetraban cartas de los soberanos, para que se les eximiera de su obedecimiento. Algunos testigos ofrecen ejemplos concretos de incumplimiento de las Ordenanzas, como el bachiller Pedro Jiménez, que recuerda que aquéllas siempre se conculcaron para la provisión de los oficios de regimiento, cubiertos por merced regia desde el año 1426.

Finalmente, la probanza de Diego de Valera se centra en otro tema candente: el carácter fraudulento de la elección que habían llevado a cabo los regidores conquenses. Evidentemente, Valera no se atrevía a apoyar sus derechos al oficio simplemente en el hecho de que al proveerle del mismo los Reyes Católicos hubieran acudido a un procedimiento sancionado por la costumbre, si bien no por el ordenamiento jurídico, que le era claramente contrario. Porque, tal como ya se ha dicho más arriba, en ningún momento se discute la existencia de las Ordenanzas, sino que se afirma la misma, y los propios testigos de Valera ofrecen datos sobre ellas, demostrando que han sido confirmadas reiteradas veces durante los años de estancia en el trono de Isabel y Fernando ${ }^{41}$.

Así las cosas, Valera, para sustentar más sólidamente sus derechos al oficio, centra su atención en la elección efectuada por los regidores, para comprobar que la misma no se realizó conforme a derecho. Para empezar, la elección no se llevó a cabo en las "casas del ayuntamiento», donde normalmente se hacían esas reuniones, sino en casa de uno de los regidores, Juan Fernández de Chinchilla, hermano del fallecido Luis de Chinchilla, que a la sazón estaba enfermo. Señala, igualmente, que la reunión se convocó apresuradamente, a pesar de que existía un plazo legal de sesenta días, pues los regidores se juntaron tan sólo dos o tres días después del fallecimiento de Chinchilla, sin dar tiempo a que regresaran a la ciudad ciertos regidores que estaban entonces fuera de la localidad y que, por tanto, no pudieron participar en la elección. Concretamente, de los doce regidores de Cuenca, tan sólo estaban presentes siete el día de la

41 El regidor Juan Álvarez, testigo en la probanza de Diego de Valera, recuerda cómo fueron confirmadas por primera vez en los prolegómenos del reinado, cuando se presentó en Segovia a dar la obediencia de la ciudad de Cuenca a la reina, que ordenó «guardar todos los privillejos, leyes, e fueros e usos que la çibdad de Cuenca tiene». Posteriormente, han sido confirmadas en otras dos ocasiones: con motivo de una visita a la ciudad de Fermando; tras la pacificación obrada en la urbe, tras una etapa de turbulencias, por mediación de una serie de enviados regios, entre los que destaca el nombre de Andrés de Cabrera. En este segundo caso se sugirió la conveniencia de promulgar unas nuevas Ordenanzas, pero aún no se ha efectuado nada en ese sentido en el momento en que se inicia el pleito. 
reunión ${ }^{42}$. Por otra parte, la elección no fue jurada en forma, y los regidores presentes no tardaron mucho en caer en la cuenta de esa carencia, por lo que intentaron reunirse una segunda vez, sólo que una carta del Consejo les impidió hacerlo. Todos estos defectos formales son confirmados explícitamente por los testigos de Valera.

Pero es que el joven escribano no se limita a señalar la lista de defectos formales que acabamos de detallar, sino que hace hincapié en la intención fraudulenta de los siete regidores que se reunieron para efectuar la elección, pues la misma se realizó con un único propósito: colocar en el oficio de escribanía del concejo de Cuenca a Juan Ramírez de Medina. Este aserto es confirmado por varios de los testigos presentados por Valera. Según Gonzalo de Beteta, existía un concierto entre Juan de Medina y Luis de Chinchilla, confirmado ante el escribano de número de Cuenca Juan del Quintanar, según el cuál se disponía el matrimonio del hijo del primero, Juan Ramírez de Medina, con la hija del segundo, Teresa Alvarez.

El concierto matrimonial sólo se llevaría a cabo si, previamente a la celebración de la boda, Chinchilla, viejo y enfermo, con poca vida por delante, renunciaba su oficio de escribanía del concejo de Cuenca en su futuro yerno. Para terminar, se establecían determinadas cautelas, en caso de que alguna de las dos partes contratantes decidiera romper el concierto unilateralmente; así, si Juan Ramírez de Medina, una vez obtenido el oficio, se negaba a casarse con su prometida, ésta recibiría una indemnización de doscientos castellanos de oro, que quedaban, como prenda, en manos de Juan Fernández de Chinchilla, tío de la novia ${ }^{43}$. Si Juan Ramírez de Medina no lograba la escribanía, recibiría, a cambio, una equivalencia ${ }^{44}$.

En estas circunstancias, la provisión del oficio en favor de Diego de Valera implicaba un duro quebranto para el concierto, que quedaba gravemente amenazado. Como ni Chinchilla ni Medina estaban dispuestos a romperlo, y gozaban, además, del apoyo de la ciudad, que veía en Valera a un nuevo escribano absentista, dispuesto a servir el oficio a través de lugartenientes, se lanzaron al ataque. Ya que sus gestiones en la Corte no daban ningún resultado positivo, decidieron utilizar, una vez muerto Chinchilla, la política de hechos consumados, haciendo caso omiso de la provisión, tratando de que la vacante se cubriera siguiendo el procedimiento establecido en las Ordenanzas de la ciudad.

${ }^{42}$ Según el regidor Juan Álvarez, los presentes fueron Juan Fernández de Chinchilla, Juan de Sacedón, García de Alcalá, Gonzalo de Beteta, Iñigo de la Muela, Alonso de Alcalá y Rodrigo de Torres.

${ }_{43}$ Resalta este hecho uno de los testigos presentados por Diego de Valera, Juan de Sacedón, regidor de Cuenca.

${ }^{4}$ Tal como afirma otro de los testigos aportados por Valera, Juan de la Bachillera. 
En este clima, un tanto enrarecido, tuvo lugar la supuesta elección de una terna por parte de los regidores, si bien Beteta afirma que no se la puede considerar tal, porque los regidores se concertaron para escoger la terna de tal modo que el beneficiado fuera siempre, en última instancia, Juan Ramírez de Medina. Por esa razón, escogieron a su propio padre, a Alonso de Ocales, que era tío de su prometida, y a Pedro de Chinchilla, también tío de Teresa Alvarez, en la seguridad de que cualquiera de ellos renunciaría el oficio en Juan Ramírez. Desconocemos porqué no se incluyó directamente en esta terna al que, en último término, iba a ser el beneficiario de la operación; tal vez, porque no reunía alguno de los requisitos mínimos para hacerse cargo del oficio: aunque es imposible comprobarlo, no parece descabellado aducir que Juan podía ser demasiado joven para ejercer el cargo por sí mismo, lo que recomendaba que se encargara del oficio su padre durante algún tiempo.

Con esto termina la probanza de Diego de Valera, que parece demostrar fehacientemente los puntos esenciales de la misma, relativos al sistema empleado en la provisión del oficio en litigio durante los últimos años y a la elección fraudulenta realizada por los regidores conquenses. Evidentemente, desde el punto de vista de Valera el quid de la cuestión radicaba en demostrar que había accedido al oficio siguiendo la vía sancionada por la costumbre, mientras que su adversario, si bien había recurrido al procedimiento que, desde el punto de vista jurídico, era más válido, había cometido, sin embargo, el error de apelar a métodos fraudulentos, al tiempo que había incurrido en numerosos defectos de forma, lo cual invalidaba la legitimidad con que, en un primer momento, parecían teñirse sus aspiraciones.

En un modesto segundo plano quedan la aptitud del propio Diego de Valera para ejercer el oficio, así como la suficiencia de sus tres adversarios. Aunque Valera también se detiene algún tiempo en estas consideraciones, lo cierto es que se trata tan sólo de unas alegaciones accesorias, destinadas a fortalecer los argumentos del escribano, que pretende, de esa manera, dejar constancia no sólo de sus más legítimos derechos al oficio, sino también de su mayor aptitud para el mismo. Pero, ostensiblemente, el punto esencial de su probanza en el relativo a la forma en que se había efectuado la provisión del oficio en su favor, así como las artimañas empleadas por su antagonista para inclinar la merced del oficio en su beneficio: la suficiencia de uno y otro es un tema secundario.

\section{La probanza de Juan de Medina}

Por su parte, la probanza de Juan de Medina comienza con un interrogato- 
rio compuesto por dieciocho preguntas, que podemos dividir en cuatro grandes apartados ${ }^{45}$ :

1) cuestiones destinadas a demostrar que Diego de Valera no es apto para desempeñar el oficio de escribano del concejo de Cuenca.

2) preguntas orientadas a probar que tanto Juan de Medina, como Alonso de Ocales o Pedro de Chinchilla, estaban perfectamente capacitados para desempeñar el citado oficio.

3) cuestiones relativas a la manera en que se había hecho merced de la escribanía a Diego de Valera, resaltando que éste había actuado maliciosamente.

4) preguntas dirigidas a comprobar que las Ordenanzas otorgadas por Fernando de Antequera a la ciudad de Cuenca se habían utilizado habitualmente desde su promulgación, y que la elección realizada por los regidores conquenses se había ajustado a las mismas; igualmente, disculpa los defectos de forma que se habían detectado en dicha elección, atribuyéndolos a la precipitación provocada por la ilegal provisión del oficio con que se había regalado a Diego de Valera.

En cuanto al primero de estos temas, Medina resalta la existencia de una serie de circunstancias que abonan la ineptitud de Valera para ejercer un oficio de tanto peso y responsabilidad como es el de escribano del concejo; para empezar, señala la extremada juventud de su contrincante, que, según los testigos de su probanza, se ha de situar en torno a los veinte años; desde luego, según la legislación en materia notarial ${ }^{46}$, esa condición dificultaba el acceso del joven al oficio, pues se establecía que el acceso a los oficios de escribanía quedaba vedado a los menores de veinticinco, con una única excepción: los hijos de escribanos que sucedían en el oficio a su padres, en cuyo caso la edad exigida descendía hasta los dieciocho años. Evidentemente, éste no es el caso de Valera, por lo que su edad, efectivamente, y siempre que se siga rigurosamente la legislación, le incapacitaba para optar al oficio.

Un segundo argumento contra la aptitud de Valera es el relativo a su condición de clérigo coronado, pues los oficios de escribanía estaban, en su

45 Presentada ante el Consejo, en Toledo, el 28 de febrero de 1480. Testificaron a su favor: Alfonso González de Huerta, escribano del número de Cuenca; Juan de Chinchilla, hijo del difunto Luis de Chinchilla; el bachiller Pedro de Alcocer; Francisco López de Huerta; Gonzalo García del Castillo, escribano del número de Cuenca, escribano de cámara de los Reyes Católicos, así como escribano de su Audiencia; Pedro de Huete, sochantre de la Catedral de Cuenca; Juan Martínez de Cañete, platero; Lope de la Barrera; Diego Gil de Soria; Fernando Zaragozano; Alfonso Ruiz de Huerta, escribano del número de Cuenca; Sancho Rodríguez de Alcocer y Diego del Castillo.

${ }^{46} \mathrm{~J}$. BONO., Op. cit., II, pp. 212 y ss. 
mayor parte, vedados a los eclesiásticos ${ }^{4}$, exigiéndose a los escribanos la pertenencia al estado laico; sin embargo, los cierto es que este requisito no siempre se cumplió, siendo no pocos los ejemplos de clérigo dedicados al ejercicio de esta profesión ${ }^{48}$. Por otra parte, Diego, aún estando "coronado", no tenía porqué pertenecer, necesariamente, al estamento eclesiástico, siendo muchos los laicos que recibían las órdenes menores y la "corona», con el único objeto de obtener las ventajas que ello comportaba.

Igualmente, Medina señala que Valera estaba en posesión de menos hacienda que sus tres contrincantes. Ya se ha visto como el propio Valera sale al paso de esta imputación en su probanza, señalando la saneada condición de su situación económica, resaltando sus no poco abundantes bienes patrimoniales. Por su parte, Medina no ofrece detalles ni respecto a su fortuna personal, ni relativos a los bienes de sus compañeros de terna. Como ya sucedía en la probanza de su contrincante, se destaca la importancia que se concedía al hecho de que el escribano fuera hombre de posibles.

Finalmente, afirma Juan de Medina que Valera no es "tan sufiçiente» para el oficio de escribanía como lo son sus tres adversarios, a pesar de que en ningún momento explica las razones que le han llevado a esa conclusión, como tampoco suministra argumentos que vayan más allá de los puramente formalistas descritos más arriba, o de las vagas consideraciones que se acaban de reseñar. Por su parte, los diversos testigos de su probanza, al referirse a esta parte del interrogatorio, tampoco se muestran más concretos.

Tampoco es capaz Medina de apuntalar convenientemente sus asertos respecto a su capacidad y la de sus compañeros de terna para desempeñar el oficio. Se limita a aseverar que cualquiera de ellos «es persona más abonada e de más días e de más actoridat e más sufiçiente e ábile para aver el dicho ofiçio e lo administrar que no el dicho Diego de Valera». Como se puede observar, se recurre también en este caso a argumentos vagos y etéreos, que resultan todo menos clarificadores. No es posible saber si los tres miembros de la terna tenían los conocimientos mínimos que se habían de exigir a un notario, si tenían un perfecto dominio del arte de la escritura, si podían aportar su experiencia personal en el campo profesional al que pertenecía el oficio en litigio... Una vez más, lo que parece evidente es que ninguno de los tres se había sometido al examen de capacitación profesional por el que, al menos teóricamente, había de

47 J. BONO., Op. cit., II, pp. 216 y ss., reseña los casos en que un religioso, de acuerdo con la legislación en materia notarial, podía ejercer la profesión de escribano, que son, de todas formas, relativamente abundantes.

48 J. BONO., Op. cit., II, p. 218, deja constancia de varios ejemplos en los que religiosos desempeñaron oficios de escribanía que les estaban vedados, según la legislación notarial. 
pasar todo aquél que deseara ejercer una escribanía. La debilidad de los argumentos empleados por Medina para tratar de probar su suficiencia para el oficio no parece dejar muchas dudas sobre el hecho de que no debían estar especialmente capacitados, pues, en caso contrario, lo habrían resaltado convenientemente.

El tercer bloque dentro de la probanza de Medina es el referido a la manera en que Valera había obtenido la provisión del oficio. Las críticas a la vía de la que se había valido el joven escribano topan con un problema de importancia, pues Diego había conseguido la merced del oficio directamente de los soberanos, cuya autoridad no se puede objetar. Así las cosas, Medina recurre a un hábil procedimiento, señalando, primero, la malicia con que había actuado Diego, y, en segundo lugar, refiriéndose a las Ordenanzas que Fernando de Antequera había otorgado a la ciudad, resaltando la fidelidad con que se habían guardado desde su promulgación.

De esta forma, Medina acusa a Valera a haber ganado el oficio cuando su antecesor aún estaba vivo, aprovechándose de su privanza con el doctor de Talavera, y valiéndose del engaño, pues no dudó en afirmar que Chichilla había fallecido ya en el momento en que él solicitaba el oficio, cuando éste vivió todavía unos veinte días. Esta versión de los hechos parece quedar ratificada gracias al testimonio del canónigo Diego del Castillo, que, al narrar sus gestiones en la Corte en favor de Luis de Chinchilla, afirma que allí se le dijo que se había hecho merced del oficio a Valera en la seguridad de que su anterior poseedor ya había pasado a mejor vida; sin embargo, otro de los testigos presentado por Medina nos ofrece una versión distinta, y hasta contradictoria, pues señala que el propio Valera había admitido ante él que la provisión del oficio por él conseguida llevaba la fecha en blanco; en este segundo caso, nos hallamos ante un hecho más que frecuente, la concesión de una carta de expectativa, que facultaba al que la recibía para ocupar un determinado oficio en el momento en que su actual poseedor falleciera.

Esta segunda versión es, realmente, la que parece más probable, así como también la que mejor encaja en las prácticas habituales del momento, pues la frecuencia con la que se otorgaban las cartas de expectativa lleva a pensar que Valera no necesitaba recurrir al engaño para obtener merced del oficio, pues podía conseguirla en vida de su antecesor, limitándose a recurrir a sus contactos en la Corte.

En cuanto a las Ordenanzas establecidas por Fernando de Antequera, remarca cómo en todo momento se había llevado a cabo en Cuenca un estricto cumplimiento de las mismas, razón por la que habían sido confirmados por los propios Reyes Católicos en diversas ocasiones. Desde el reinado de Juan II, esas Ordenanzas se habían utilizado sin merma ni variación alguna para la provisión del oficio en litigio, contrariamente a lo que Valera afirmaba en su 
probanza. Así, según la versión que de los hechos nos ofrece Juan de Medina, a la muerte de Juan López en el año 1436 había sido el concejo conquense el que tomo la iniciativa de cara a la cobertura del oficio vacante, siendo el resultado de la reunión de los regidores de la ciudad la terna compuesta por Juan Sánchez de Sarrión, Álvar González de Huerta y Pero López de Torralba, siendo el primero de los tres el que logró hacerse con la escribanía.

Años después, cuando se produjo una nueva vacante del oficio, se hizo con la merced del mismo el hijo del difunto escribano, Juan de Sarrión, que había compartido terna con Alfonso López de Santorcaz y Pero Fernández de la Vieja, aunque en este caso Medina se vió obligado a reconocer que la ciudad no deseaba recibir como escribano a Sarrión, sino a López de Santorcaz, pero los regidores no tuvieron más remedio que conformarse a la voluntad del Conde de Buendía, que se impuso a los deseos de la urbe, si bien el respeto hacia las Ordenanzas les llevó, tal como indica Francisco López de Huerta, testigo presentado por Juan de Medina, a simular la existencia de una auténtica elección por parte de los regidores.

Nada se indica sobre el acceso al oficio por parte de Pedro de Sarrión, indudablemente porque se llevó a cabo fuera de los márgenes establecidos por las Ordenanzas, ya que fue producto de la renunciación que en su favor efectuó su hermano y antecesor en el mismo. Otro es el caso de la provisión en favor de Luis de Chinchilla, sobre la que Medina ofrece diversos detalles, ya que se trata de una ocasión en la que sí parece haberse realizado la provisión de la vacante de acuerdo con las Ordenanzas de la ciudad. $\mathrm{Ni}$ que decir tiene que en esta probanza no se hace ninguna referencia a los problemas que enfrentaron al concejo y a Chinchilla con el Conde de Buendía, como tampoco se mencionan en ningún momento las maniobras orquestadas por Chinchilla para hacerse con el oficio, ni los supuestos desembolsos económicos que se vio obligado a hacer para obtener aquél ${ }^{49}$.

Para avalar su versión de los hechos, Medina presenta como testimonio el registro del escribano del concejo de Cuenca correspondiente al año 1436 y, concretamente, una entrada fechada a veintiuno de septiembre del citado año, en la que se contiene el acta de la elección efectuada ese día por los regidores conquenses, con objeto de cubrir la vacante que había producido en la escriba-

49 Por su parte, el Conde de Buendía, en su declaración como testigo de la probanza de Diego de Valera, insiste en que Juan II le había concedido la merced de proveer el oficio en quien él deseara, cosa que también habría hecho tras la muerte de Pedro de Sarrión, si no hubiera sido porque Álvaro de Luna «se atravesó e ynpidió la dicha merçed que el dicho Conde tenía ganada del dicho ofiçio para el dicho su criadon. La suplicación de los regidores de Cuenca a favor de Chinchilla y sus compañeros de terna se fechó en esa ciudad, a 28 de octubre de 1452 . 
nía del concejo la muerte de Juan López, elección que llevó, en última instancia, y tal como ya queda dicho, a la provisión del oficio en favor de Juan Sánchez de Sarrión. Medina presenta, al mismo tiempo, tres testigos, con objeto de que éstos identifiquen la caligrafía del documento, para así garantizar su autenticidad, tal como efectivamente hacen ${ }^{30}$.

Sin embargo, la prueba presentada por Juan de Medina no parece resistir el examen que de la misma hacen Valera y los testigos por él aportados para analizarla ". Valera que se trata, evidentemente, de una falsificación, señalando las razones que le impelen a pensar así: el acta no está signada, ni señalada de escribano público, tal como lo están las demás contenidas en el registro; la caligrafía difiere de aquélla en la que está realizado el resto del registro; la hoja no está encuadernada en el tomo del registro, sino cosida; detrás de la hoja en cuestión han sido arrancadas otras, que se cortarían por contener «cosas que farían contra ellos». Como se trataba de la última hoja de ese tomo del registro, para disimular habían cosido detrás suyo un cuadernillo, que queda situado en una colocación incorrecta, por los asuntos que en él se tratan y las fechas a las que responde. Por último, afirma que el autor de la falsificación ha sido Alfonso González de Huerta -uno de los testigos presentados por Medina para ratificar la autenticidad del acta-, escribano del número de Cuenca, que «a fecho e fabricado muchas scripturas falsas en la dicha çibdad çerca de su ofiçio, e por tal ha sido acusado e sentençiado por falsario».

Aunque Medina se apresura a contestar, negando la falsedad del acta y tratando de proteger la reputación del escribano infamado ${ }^{\prime 2}$, lo cierto es que no es capaz de presentar pruebas que ratifiquen esta declaración y alejen las sospechas levandas por Valera ${ }^{33}$, mientras que este último presenta una serie de

so Estos testigos son Alfonso González de Huerta, hijo de Álvar González de Huerta, el supuesto calígrafo del acta; Alfonso Ruiz de Huerta y Sancho Rodríguez de Alcocer. Los tres se muestran dispuestos a ratificar la autenticidad del documento. 1480.

"1 Este escrito es presentado en Toledo, ante el Consejo, el día quince de abril de

"2 Tal como consta por su escrito, presentado ante el Consejo en Toledo, el 20 de abril de 1480 .

33 De esta circunstancia da cuenta Valera al Consejo el día 6 de junio de 1480, señalando que Medina había sido incapaz de encontrar testigos que con sus deposiciones alejaran la duda que planeaba sobre el acta de 1436 por la que Medina trataba de demostrar que tras la muerte de Juan López se había cubierto su escribanía recurriendo a las Ordenanzas de Fernando de Antequera. Medina contesta a su adversario, rogando al Consejo un nuevo plazo para presentar testigos, el día 13 de junio, pero Valera contraataca el día siguiente, exigiendo al Consejo que no se le otorgue más término, logrando, tras esa alegación, que el pleito quede visto para sentencia. 
testigos que documentan sus imputaciones, fundamentalmente las relativas a la maltrecha reputación de Alfonso González de Huerta ${ }^{44}$.

El último aspecto de la probanza de Medina es el relativo a la manera en que los regidores conquenses habían efectuado la elección con objeto de cubrir la vacante producida por el óbito de Luis de Chinchilla. Evidentemente, su propósito es justificar los defectos formales que se habían detectado en la misma. Así, Medina reconoce que, a pesar de que disponían, a tenor de las Ordenanzas, de un plazo que se extendía hasta sesenta días después de la muerte de Chinchilla para proceder a la elección, ésta se había efectuado tan sólo dos o tres después, y si se hizo «arrebatadamente e en tan breve tiempo», fue porque querían que la suplicación de los regidores en favor de la terna llegara a los monarcas en el menor tiempo posible, antes de que se diera la provisión definitiva del oficio a Diego de Valera.

Reconoce que no todos los regidores estuvieron presentes en la reunión. Faltaban el mayordomo Andrés de Cabrera, su hermano, Alfón de Cabrera, y Pedro de Barrientos, que residían habitualmnete en la Corte, razón por la que no tenían voto. Igualmente, faltaron Juan de Molina y Juan Álvarez, si bien este último -tal como afirma en la probanza de Diego de Valera-, informado de la sucedido, se avino a aceptar la elección.

A continuación, Medina trata de justificar que la reunión no se llevara a efecto en las casas del ayuntamiento, sino en el domicilio de Juan Fernández de Chinchilla, asegurando que se hizo así porque este regidor se hallaba enfermo, y era práctica habitual, en esos casos, hacer las reuniones en la casa del convaleciente.

Reconoce, por último, que la elección no fue jurada en forma, circunstancia de la que no fueron conscientes los regidores conquenses hasta que la suplicación no llegó a la Corte. Así las cosas, pretendieron reunirse una segunda vez, con objeto de paliar todos los defectos formales que se habían cometido en la primera ocasión, pero recibieron una carta del Consejo que les prohibía hacerlo, por lo que los defectos no pudieron ser subsanados. Sea como sea, Medina achaca estos defectos, en última instancia, a la precipitación que

${ }^{44}$ En este sentido, Valera presenta un interrogatorio tendente a demostrar que Alfonso González de Huerta tenía reputación bien ganada de falsario, pues había usado poco éticamente de su profesión confeccionando escrituras falsas, lo que le había conducido a una difícil situación, ya que había sido sentenciado por ese quebrantamiento de sus deberes profesionales. Los testigos que presenta -Pedro de la Mota y Alfonso de Salmerón- ratifican todos los puntos contenidos en el interrogatorio. De todas formas, tampoco fue sencillo para el joven escribano encontrar testigos dispuestos a deponer contra el escribano falsario, pues se había visto obligado a pedir una ampliación del plazo que para ello le había otorgado el Consejo, como consta por un escrito suyo presentado el 3 de junio, en el que achaca dificultades a la inactividad causada por una grave enfermedad que había padecido. 
imprimió a las acciones de los regidores la expectativa en favor de Valera, pues «sy algund defecto ovo en ella fue por esta causa».

También en esta probanza, como en la de Valera, el aspecto fundamental es el referido al sistema que se había empleado para efectuar la provisión del oficio, siendo los demás puntos de la misma puramente accesorios. Sin embargo, contrariamente a lo que sucedía con la de Valera, la probanza de Medina se revela, en gran medida, fallida. Es incapaz de demostrar, con argumentos válidos y convincentes, la ineptitud de su antagonista para el ejercicio del oficio. Paralelamente, tampoco es capaz de probar su propia suficiencia y la de sus dos compañeros de terna. No se atreve a realizar ninguna objeción al sistema por el que Valera se ha visto favorecido con el oficio, limitándose a señalar que éste actuó maliciosamente al conseguir la provisión en su beneficio.

Tampoco puede comprobar satisfactoriamente que las Ordenanzas otorgadas a Cuenca por Fernando de Antequera se emplearan en esa ciudad de manera estricta y habitual, e incluso su intento en ese sentido abre grandes dudas respecto a su propia honorabilidad, pues parece que, ante la ausencia de pruebas veraces y auténticas, recurre al engaño y a la falsedad. Por último, se ve obligado a reconocer que la elección realizada por los regidores conquenses estuvo plagada de defectos formales, sin que ofrezca argumentos que justifiquen los mismos, de entrada difícilmente justificables.

\section{LA SOLUCIÓN DEL CONFLICTO}

La documentación relativa al pleito termina, abruptamente, una vez que, ya avanzado el mes de junio, el Consejo declara el pleito por concluso y a la espera de sentencia, sin que conste ésta. Nuestra fuente principal, por tanto, nos hurta la solución del conflicto, solución que conocemos gracias a un documento fechado en Medina del Campo, a once de Octubre de 1480, por el que se provee el oficio de escribanía del concejo de Cuenca en favor de Juan de Medina, por renunciación de Diego de Valera".

El citado documento nos ofrece los datos que permiten reconstruir, con ciertas lagunas, lo sucedido desde el mes de junio. Destaca, en primer lugar, un hecho, y es que, en suma, no se puso punto y final al conflicto a través de una sentencia judicial, sino por medio de un concierto entre las partes, que debían estar, ambas, interesadas en llegar a un acuerdo: Valera, porque para él debía ser más que evidente que no era bien recibido en Cuenca, lo que, unido al hecho, más que probable, de que no pudiera servir directamente el oficio, pudo hacer que se decantara por una solución amigable, que excluyera su presencia

"Archivo General de Simancas, Registro General del Sello, Medina del Campo, 11-10-1480, fol. 4. 
en Cuenca. Medina, porque una sentencia hubiera favorecido, casi con total seguridad, a su contrincante, no sólo porque éste había presentado una probanza mucho más sólida, si no también por el casi seguro apoyo que le prestaba el Doctor de Talavera, uno de los miembros más influyentes del Consejo durante los primeros años de reinado de Isabel y Fernando.

El que la definitiva provisión del oficio se dilatara hasta el mes de Octubre, cuando el proceso ya estaba visto para sentencia en el mes de junio, puede ser indicio de las dificultades que se hubieron de superar hasta llegar al concierto entre las partes, concierto que debió favorecer sustancialmente a Valera, ya que era el que se hallaba en mejor situación. Lo que no es posible es establecer los términos sobre los que se construyó el acuerdo. Cabe preguntarse si Medina se hubo de plegar, al final, a las exigencias económicas que Valera había manifestado, meses atrás, al canónigo Diego del Castillo.

Una vez en posesión del oficio, Juan de Medina no lo renunció, tal como era de esperar, en su hijo, sino que desempeñó la escribanía por sí mismo, al menos hasta el año $1485^{\circ 6}$, sin que sea posible determinar porqué no efectuó la prevista renunciación en favor de Juan Ramírez de Medina. Tal vez, era éste demasiado joven para servir el oficio, o quizá Medina decidió disfrutar durante algunos años de aquello que tanto le había costado conseguir.

\section{CONCLUSIONES}

El pleito estudiado nos permite observar cuáles eran las consideraciones que se tenían en cuenta de manera fundamental a la hora de efectuar la provisión de un oficio de escribanía; igualmente, el proceso concede la posibilidad de establecer las diferencias entre la teoría, representada por la legislación en materia notarial, y la práctica, materializada en los aspectos que, de acuerdo con el tenor del pleito, eran tenidos en cuenta a la hora de facilitar el acceso al ejercicio notarial.

El proceso gira, primordialmente, en torno a una cuestión: el sistema empleado para proveer el oficio en litigio, oponiéndose dos posibles vías; la primera, la de la provisión por parte del monarca correspondiente, que, haciendo uso de su autoridad, no duda en intervenir en la vida de los concejos, arrogándose un privilegio que no le pertenece de derecho, pero que acaba siendo sancionado por la costumbre. La segunda es la provisión por parte del concejo, que se apoya en las ordenanzas locales, tratando de defenderse, frente al intervencionismo, constante e irritante, de la Corona.

Ambos procedimientos son susceptibles de abusos y corruptelas. El prime-

36 Se conserva, en el Archivo General de Simancas, Registro General del Sello, documentación que corrobora este hecho: Vitoria, 12-12-1483, fol. 101; Córdoba, 12-41485, fol. 323; Córdoba, 28-4-1480, fols. 319 y 326. 
ro, porque se corre el riesgo de colocar la provisión de estos oficios -como claramente se observa en el pleito- en manos de privado y válidos, pero también porque se tiende a favorecer a aquéllos que gozan, bien del favor regio, bien del de los más legales servidores de la Corona. El segundo, porque, en múltiples ocasiones, las ordenanzas se conculcan en favor de los poderosos locales, que hacen y deshacen a su antojo, situando en el oficio a gente de su agrado. En ambos casos, por tanto, existe el peligro de proveer en favor de personas no capacitadas para el ejercicio de los oficios, lo que es especialmente perceptible en el caso de aquéllos que exigen una formación previa en las personas que los van a desempeñar, como es el caso de las escribanías.

Lo cierto es que este último aspecto se hace, con mucha frecuencia, accesorio y secundario, cuando debería ser primordial. En el caso concreto del pleito estudiado, no se presta especial atención a la capacitación profesional de ambos aspirantes al oficio de escribanía del concejo de Cuenca. Para empezar, no existe ninguna mención a ese examen al que -al menos, teóricamente-, había de enfrentarse todo aquél que deseara ejercer profesionalmente como escribano; en estas condiciones, cabe dudar de la asiduidad con la que se celebraba el citado examen, así como también de la eficacia del mismo, desde el momento en que parece ostensible que, al menos en ciertos casos, se podía acceder a una escribanía sin tener que afrontarlo necesariamente, ya que se trata de un requisito que no se exige a ninguno de los dos contendientes.

Por otra parte, las exigencias de carácter profesional no parecen ir más allá de las relativas al conocimiento del arte de la escritura, así como a la existencia de cierta experiencia en el ejercicio profesional de la escribanía, mientras que no se alude en ningún momento a la formación que, teóricamente, se había de recibir bajo la autoridad de escribanos duchos en su profesión, como tampoco se menciona la necesaria posesión de ciertos conocimientos: gramaticales, jurídicos, de formularios documentales...

Mayor interés parece ponerse en los requisitos de índole personal. Aspectos como la edad de los aspirantes, su situación económica, su carácter de personas honradas y su condición de vecinos de la ciudad de Cuenca parecen recibir una mayor consideración y atención, como se si tratara de lo realmente fundamental a la hora de desempeñar un oficio de escribanía.

Se hace ostensible que la legislación en materia notarial, tan estricta y completa, difícilmente se cumplía en la práctica, pues lo cierto es que, a la hora de proveer la vacante de un oficio de escribanía, podía suceder que la provisión no se efectuara en consonancia con las disposiciones de la legislación, dejándose de lado las consideraciones profesionales, teniéndose en cuenta, en el mejor de los casos, tan sólo los requisitos de carácter personal, recayendo los oficios en aquéllos que contaban con apoyos y contactos, capaces de pulsar los resortes del poder. Y los propios Reyes Católicos, que trabajaban a favor de una reconstruc- 
ción de la maltrecha institución notarial, no siempre supieron estar al margen de estos episodios, que a veces se produjeron, como es el caso, con su anuencia y bendición.

\author{
MARÍA DEL PILAR RÁBADE OBRADÓ \\ Universidad Complutense de Madrid
}

\title{
RÉSUMÉ
}

Voici une analyse de quelques-uns des traits principaux qui déterminent la singulière situation dans laquelle se trouvait plongée l'institution notariale vers la fin du Moyen Age, situation dominée par l'ostensible contradiction existant entre la stricte législation et l'usure de sa mise en pratique. Cette contradiction est mise en évidence dans le pourvoi des charges de greffier en titre et du Conseil Municipal, mesure qui dégénérait fréquemment en violents conflicts entre la Couronne et les Conseils Municipaux, sans qu'aucun des deux chemins possibles de pourvoi soient absolument exempts d'abus et de corruption, car dans les deux cas les charges pouvaient pourvoir en faveur de ceux qui savaient ou pouvaient mouvoir les ressorts du pouvoir, ignorant les exigences de capacité professionnelle. Les Rois Catholiques eux-mêmes, qui s'efforcèrent tant, dans les États Généraux de Tolède de 1480, de réorganiser l'institution notariale, en piteux état après les règnes de Jean II et d'Henri IV, ne parvinrent pas à supprimer ce genre de pratiques.

\section{SUMMARY}

In this study, we analyze some of the main lines that guide the special situation of the notary institution just after the Middle Ages. This situation is characterised by the conspicuous contradiction between the strict legislation and the weariness to implement it. This contradiction becomes evident in the distribution of charges of titular clerk and clerk of the Municipal Council. The distribution used to degenerate in dense conflicts between the Crown and the Municipal Council and none of the two possible ways of allocation was totally free of abuses and corruption, since in both cases the charges could favorise those who knew how to have an influence on the power, not attending the requeriments of professional abilites. Nobody managed to escape this kind of practice, not even the Catholic Kings who tried so much, during the "Cortes" of Toledo in 1480 , to reorganize the notary institution so ill-treated after the reigns of Juan II and Enrique IV. 